\title{
Effect of Complex Training Program on Physical Fitness, Derivatives Reactive Oxygen Metabolite and Biological Antioxidant Potential Levels of Adolescents with Intellectual Disabilities
}

\section{G. Kim ${ }^{1}$ and J. S. Lee ${ }^{2}$}

${ }^{1}$ Department of Sports Science, Gachon University, Bokjeong-dong, Seungnam, Republic of Korea

${ }^{2}$ Department of Physical Education, Korea University, Anam-dong, Seoul, Republic of Korea

\begin{abstract}
Aim: The purpose of this study was to examine the effects of complex exercise program on physical fitness, derivatives reactive oxygen metabolite (d-ROM) and biological antioxidant potential (BAP) levels of adolescents with intellectual disabilities, and to sugesst exercise programs to promote the health and physical development of such adolescents.

Methods: Sixteen students with intellectual disabilities were divided into 2 groups (Age: $13.37 \pm 2.36$ yrs, Height: $155.63 \pm 9.72 \mathrm{~cm}$, Weight: $63.24 \pm 11.25 \mathrm{~kg}$ ); exercise group $(\mathrm{n}=8)$, control group $(\mathrm{n}=8)$. The exercise group performed the complex exercise program 60 minutes a day, 3 times a week over a 12-week period. Then, the control group maintained their activities of daily living. Before and after the completion of the training programm, and physical fitness were measured and blood samples were assessed.

Results: The results of the study indicate that the 12-weeks complex exercise program increased significantly health- and skill-related. Furthermore, the d-ROM levels decreased more significantly in the exercise group than in the control group, and the BAP levels decreased after completion of the exercise program in the exercise group.

Conclusion: This study proved that the complex exercise program improved physical fitness, and reduced the d-ROM levels of the adolescents with intellectual disabilities. Therefore, it may enhance the health and physical development of adolescents with intellectual disabilities.
\end{abstract}

\section{Introduction}

The social interest in people with disabilities has increasingly become an interest in welfare in today's society. In particular, adolescents with intellectual disabilities are restricted to their personal environment because their limited health- and growth-related physical activities. Therefore, they need more social concern.

People with intellectual disabilities have lower-than-average intellectual levels, and in particular, adolescents with intellectual disabilities have higher risks for cardiovascular disease and obesity that lead to type 2 diabetes mellitus via hypoactivity [1,2]. Compared with people without intellectual disabilities, they have slower walking speed because of their inability to control balance, coordination well [3], and perform physical activities efficiently with their weakened muscular strength, endurance, agility, and motor reaction [4].

Furthermore, people with intellectual disabilities tend to have high levels of reactive oxygen species (ROS) due to hypoactivity. More than $95 \%$ of ingested oxygen in the human body is combined with electrons produced from the energy metabolism of cells and reduced to water, but $2-3 \%$ of oxygen is reduced incompletely and generates free radicals [5,6]. Excessive physical activity causes formation of free radicals that leads to increases in oxidative stress and, finally, to negative effects $[7,8]$. However, the human body deals with ROS through its antioxidant capacity, which can be increased by regular physical activity $[9,10]$.

Adolescents with intellectual disabilities lack physical activity, which not only inconvenience daily life but also confers potential health risks with the reduced basic physical fitness. Therefore, it is important for such adolescents to work out regularly to improve their performance in activities in daily life and general health.

Generally, regular aerobic exercise has positive effects on body composition; similarly, resistance exercise also improves body composition by improving oxidative energy metabolic capability $[11,6]$. Advanced research studies on exercise, which investigated the effects of aerobic exercise on ROS levels and antioxidant capacity [12-14] and the effects of resistance exercise on oxidative stress levels and antioxidant capacity [15-17], demonstrated the positive effects of aerobic and anaerobic exercises on ROS levels and antioxidant capacity. However, the subjects of these studies were people without disabilities, and data from research studies on the effects of regular exercise on ROS levels and antioxidant capacity in adolescents with intellectual disabilities are not sufficient to be conclusive.

When designing an exercise program for adolescents with intellectual disabilities, findings from studies on the effects of regular exercise on body composition, physical fitness, oxidative stress levels, and antioxidant capacity should be considered. Adolescents with intellectual disabilities have weakened body coordination and movement ability as results from their inability to smoothly control muscle groups in each body part [18], and they are easily distracted, making their attention span short. Therefore, repeated general anaerobic exercise may be undesirable.

A new exercise program should be developed for adolescents with intellectual disabilities that could enhance their body balance and that involves frequent changes in body movement to prevent them

${ }^{*}$ Corresponding Author: Dr. J. S. Lee, Exercise Physiology, Department of Physical Education, Korea University, Anam-dong, 136-701, Seoul, Republic of Korea; E-mail: stay1000@korea.ac.kr

Citation: Kim CG, Lee JS (2016) Effect of Complex Training Program on Physical Fitness, Derivatives Reactive Oxygen Metabolite and Biological Antioxidant Potential Levels of Adolescents with Intellectual Disabilities. Int J Phys Ther Rehab 2: 115. doi: http://dx.doi.org/10.15344/2455-7498/2016/115

Copyright: ( $2016 \mathrm{Kim}$ et al. This is an open-access article distributed under the terms of the Creative Commons Attribution License, which permits unrestricted use, distribution, and reproduction in any medium, provided the original author and source are credited. 
Citation: Kim CG, Lee JS (2016) Effect of Complex Training Program on Physical Fitness, Derivatives Reactive Oxygen Metabolite and Biological Antioxidant Potential Levels of Adolescents with Intellectual Disabilities. Int J Phys Ther Rehab 2: 115. doi: http://dx.doi.org/10.15344/2455-7498/2016/115

Page 2 of 5

from being bored, with consideration of their features rather than just just repeating simple exercises.

Therefore, this study aimed to develop an exercise program for the health improvement and growth development of adolescents with intellectual disabilities by examining the effects of complex exercise program on physical fitness, derivatives reactive oxygen metabolite (d-ROM) level, and biological antioxidant potential (BAP) levels with consideration of the features of adolescents with intellectual disabilities.

\section{Materials and Methods}

\section{Participants}

Sixteen adolescents with intellectual disabilities between 10 and 16 years old who were from Incheon city participated in the study(Age: $13.37 \pm 2.36$, Height: $155.63 \pm 9.72$, Weight: $63.24 \pm 11.25)$. The participants were judged to have class 1,2, or 3 intellectual disabilities, and could be rehabilitated in society and profession by education. This study was approved by the Department of Sports Sciences, University of Gachon, and complied with the requirements for human experimentation. After medical screening to rule out any conditions that might have precluded their participation, all the subjects provided written informed consent.

\section{Study design}

To examine the effects of complex exercise program on physical fitness, d-ROM and BAP levels, we conducted the participants in the exercise group to exercise 3 times per week for 12 weeks. The height, weight, were measured before using an automatic height/ weight measurement system (BSM340, Biospace Co., Korea). Body composition and physical fitness were measured and blood samples were obtained before and after the completion of the exercise program.

\section{Physical fitness}

Health- and skill-related fitness were measured separately to assess fitness according to the effects of complex exercise program oriented toward balance reinforcement.

A basic fitness measurement system (THP2, Nurytec Co., Korea) was used to assess the health-related fitness and muscular strength (grip and back strengths), and measure muscular endurance (situp) and flexibility (sit and reach). To measure grip strength, the participants were trained to squeeze a dynamometer as hard as they could; measurement was performed twice for each hand, recording the higher value. In case of back strength, they were trained to pull utmost only with waist force while holding bars, with their backs straightened; measurement was performed twice, recording the higher value. For the sit-up measurements, beginning with a lying position, the participants were trained to lift their upper body up to the angle of a sensor, holding the position for 1 minute to allow the sensor to record the movement and then the total number of sit-ups made. In the sit-and-reach measurement, the subject stretched the upper body and hands forward, seating with the feet stretched, soles fixed to the measurement stand, with one hand on the other hand. Measurement was performed twice, with the higher mark recorded.

Hexagon agility and lower-quarter Y-balance tests were conducted to assess skill-related fitness. The hexagon agility test is the usual method of measuring quickness by measuring visual reaction, timing, and rate of physical reaction. The participants had sufficient practice of the exercises before the measurements were performed, and the highest record was adopted after two measurements in clockwise and counterclockwise directions.

In addition, the lower-quarter Y-balance test was used to test functional balance ability. After measuring the length of the legs, the maximum frontal, posterior, medial, and lateral distances were measured without losing balance, keeping the balance with the other foot. The higher mark was recorded after exercising with two feet alternately.

All the measurements were conducted after the participants had sufficient training on the exercises, considering the fact that adolescents with intellectual disabilities take longer time to learn the exercises than people without disabilities.

\section{Analysis of d-ROM and BAP levels}

Blood samples were collected 7 days before and 3 days after completion exercise program. The participants remained in a hunger state for 8 hours and were forbidden to engage in extreme sports until blood sampling from the fingertip capillary. The d-ROM and BAP tests were used to assess oxidative stress and antioxidant capacity levels $[19,20]$, using the International Scientific Community-certified oxidative stress analysis system. Measurement of the d-ROM levels were based on the ability of transition metals to catalyze, in the presence of peroxides, the formation of free radicals, which are trapped by an alchilamine. The d-ROM level was expressed as CARR U. It has been established that 1 CARR U corresponds to $0.08 \mathrm{mg} / \mathrm{dL}$ hydrogen peroxide $[19,21]$ From the manugacturer's instructions, the following classigication was made: very high oxidative stress, above 500 CARR U; high oxidative stress, from 401 to 500 CARR U; slight oxidative stress, from 321 to 340 CARR U; border-line, from 301 to 320 CARR U; and normal, from 250 to 300 CARR U. The BAP levels were expressed as $\mu \mathrm{mol} / \mathrm{L}$. The manufacturer's instruction shows the following classigication: optimum range, from 2,201 to $4,000 \mu \mathrm{mol} / \mathrm{L}$; border line, from 2,001 to $2,200 \mu \mathrm{mol} / \mathrm{L}$; moderate shortage from 1,801 to $2,000 \mu \mathrm{mol} / \mathrm{L}$; shortage, from 1,601 to $1,800 \mu \mathrm{mol} / \mathrm{L}$; severe shortage, from 1,401 to $1,600 \mu \mathrm{mol} / \mathrm{L}$; and very severe shortage, less than $1,400 \mu \mathrm{mol} / \mathrm{L}$.

\section{Complex exercise program}

In this study, the complex exercise program was conducted for 60 minutes per session, 3 times every 12-weeks. The total exercise program consists of warming up for 10 minutes, exercising for 40 minutes, and cooling down for 10 minutes. The participants mainly did stretching for warm-up and cool-down, and used tools such as an elastic band and swiss ball in exercises for balanced muscular strength development. In weeks 1 and 2, they were acquainted on the use of the tools within 7-9 degrees of intensity (very light to a little light) according to the ratings of perceived exertion (RPE); from weeks 3 to 12 , the exercise intensity was increased from 1 or 2 sets to 2 or 3 sets. TheraBand elastic bands (Hygenic Corp., Akron, OH, USA) were used in the resistance exercises. The exercise intensity was set between 11 and 15 on the Bog scale, using yellow bands $(0.5-1.3 \mathrm{~kg})$ initially and gradually increasing to red $(0.7-1.8 \mathrm{~kg})$. Either a $45-$ or $55-\mathrm{cm}$ diameter swiss ball was used, depending on the height of the subject. The components of the exercise program are detailed in Table 1. In this study, a trainer assisted the participants, considering that they had intellectual disabilities and were not used to the exercises. 
Citation: Kim CG, Lee JS (2016) Effect of Complex Training Program on Physical Fitness, Derivatives Reactive Oxygen Metabolite and Biological Antioxidant Potential Levels of Adolescents with Intellectual Disabilities. Int J Phys Ther Rehab 2: 115. doi: http://dx.doi.org/10.15344/2455-7498/2016/115

Page 3 of 5

\begin{tabular}{|c|c|c|c|}
\hline Variable & 1-2 weeks & 3-7 weeks & 8-12 weeks \\
\hline Warm-up & \multicolumn{3}{|c|}{$\begin{array}{l}\text { Stretching } \\
\text { neck, shoulder, arm, wrist, leg, ankle, etc. for } 10 \\
\text { min, RPE7-9 }\end{array}$} \\
\hline $\begin{array}{l}\text { C o m p l e } x \\
\text { exercise }\end{array}$ & $\begin{array}{l}\text { Conditioning } \\
40 \mathrm{~min}, \mathrm{RPE} 7- \\
9\end{array}$ & $\begin{array}{l}\text { elastic-band } \\
\text { arm curl, } \\
\text { triceps } \\
\text { extension, } \\
\text { lateral raise, } \\
\text { shoulder } \\
\text { press, and } \\
\text { chest press, } \\
\text { each, } 10-15 \\
\text { repetitions, } \\
1 \text { or } 2 \text { sets, } \\
\text { RPE } 11-13 \\
\text { intensity, rest } \\
\text { for } 1 \text { min } \\
\text { swiss ball } \\
\text { back extension, } \\
\text { hip bridge, } \\
\text { squat, twist } \\
\text { lunge, leg curl, } \\
\text { and crunch; } \\
10 \text { repetitions, } \\
1 \text { of } 2 \text { sets, } \\
\text { RPE } 11-13 \\
\text { intensity, rest } \\
\text { for } 1 \text { min }\end{array}$ & $\begin{array}{l}\text { elastic-band } \\
\text { crunch, back } \\
\text { extension, hip } \\
\text { flexion, hip } \\
\text { extension, } \\
\text { leg extension, } \\
\text { and leg curl; } \\
\text { each, 10-15 } \\
\text { repetitions, } \\
2 \text { or } 3 \text { sets, } \\
\text { RPE } 13-15 \\
\text { intensity, rest } \\
\text { for } 1 \text { min } \\
\text { swiss ball } \\
\text { bear walking, } \\
\text { push-up, } \\
\text { dumbbell } \\
\text { press, shoulder } \\
\text { press, } \\
\text { dumbbell } \\
\text { biceps curl, } \\
\text { and one- } \\
\text { hand triceps } \\
\text { extension; } 10 \\
\text { repetitions, } \\
2 \text { or } 3 \text { sets, } \\
\text { RPE } 10-12 \\
\text { intensity, } \\
\text { RPE } 13-15 \\
\text { intensity, rest } \\
\text { for } 1 \text { min }\end{array}$ \\
\hline Cool-down & \multicolumn{3}{|c|}{$\begin{array}{l}\text { Stretching } \\
\text { neck, shoulder, arm, wrist, leg, ankle, etc. for } 10 \\
\text { min, RPE7-9 }\end{array}$} \\
\hline
\end{tabular}

\section{Statistical analysis}

A statistical analysis was performed using the SPSS ver. 21.0 statistical program, and mean and standard deviations were calculated as descriptive statistics. An independent $t$ test was performed to compare the 2 groups, and a paired t test was used to compare the changes between the before ( 0 -week) and after (12-weeks). Statistical significance was set at $\alpha=.05$.

\section{Results}

\section{Changes in physical fitness after 12-weeks complex exercise} program

Health- and skill-related fitness were measured to evaluate the fitness changes after 12-weeks complex exercise program (Table 2 and $3)$.

Among the health-related fitness factors, right-left grip strength, back strength, muscular endurance, and flexibility were significantly increased after 12-weeks $(p<.05)$ (Table 2). In the control group, back strength significantly decreased after 12 -weeks $(p<.05)$. In particular back strength more significantly increased in the exercise group than in the control group $(p=.070)$.

\begin{tabular}{|c|c|c|c|c|}
\hline \multirow[b]{2}{*}{ Variable } & \multicolumn{2}{|c|}{ Exercise Group $(\mathrm{n}=8)$} & \multicolumn{2}{|c|}{ Control Group $(\mathrm{n}=8)$} \\
\hline & Before & After & Before & After \\
\hline $\begin{array}{l}\text { Right grip } \\
\text { strength }(\mathrm{kg})\end{array}$ & $13.52 \pm 8.26$ & $16.12 \pm 7.32^{*}$ & $14.29 \pm 9.38$ & $15.011 \pm 9.46$ \\
\hline $\begin{array}{l}\text { Left grip } \\
\text { strength }(\mathrm{kg})\end{array}$ & $12.61 \pm 8.13$ & $15.22 \pm 8.86^{*}$ & $13.94 \pm 8.15$ & $14.12 \pm 7.13$ \\
\hline $\begin{array}{l}\text { Back strength } \\
(\mathrm{kg})\end{array}$ & $22.47 \pm 12.14$ & $26.90 \pm 13.91^{*}$ & $21.89 \pm 13.21$ & $17.77 \pm 14.15^{\star}$ \\
\hline Sit-up (count) & $8.43 \pm 6.51$ & $11.12 \pm 7.66^{*}$ & $9.27 \pm 8.62$ & $10.61 \pm 7.77$ \\
\hline $\begin{array}{l}\text { Sit and reach } \\
(\mathrm{cm})\end{array}$ & $-2.38 \pm 6.26$ & $3.22 \pm 5.87^{\star}$ & $-1.72 \pm 4.25$ & $1.12 \pm 7.23$ \\
\hline \multicolumn{5}{|c|}{ Table 2 . The changes in health fitness after 12-weeks exercise program } \\
\hline \multicolumn{5}{|c|}{$\begin{array}{l}\text { The data are presented as mean } \pm \text { SD values. } \\
{ }^{\star} \text { Significant }(\mathrm{p}<.05) \text { difference between the baseline and } 12 \text {-week periods. }\end{array}$} \\
\hline
\end{tabular}

\begin{tabular}{|c|c|c|c|c|}
\hline \multirow[b]{2}{*}{ Variable } & \multicolumn{2}{|c|}{ Exercise Group $(\mathrm{n}=8)$} & \multicolumn{2}{|c|}{ Control Group $(\mathrm{n}=8)$} \\
\hline & Before & After & Before & After \\
\hline $\begin{array}{l}\text { Right-turn } \\
\text { hexagon agility } \\
\text { test (sec) }\end{array}$ & $31.09 \pm 17.53$ & $22.67 \pm 12.12$ & $29.47 \pm 15.63$ & $28.69 \pm 16.23$ \\
\hline $\begin{array}{l}\text { Left-turn } \\
\text { hexagon agility } \\
\text { test (sec) }\end{array}$ & $33.58 \pm 24.46$ & $22.32 \pm 21.97$ & $21.88 \pm 8.89$ & $21.16 \pm 9.68$ \\
\hline $\begin{array}{l}\text { Right-foot } \\
\text { Lower-quarter } \\
\text { Y-balance test } \\
\text { (sec) }\end{array}$ & $34.04 \pm 10.07$ & $43.26 \pm 9.28^{\star}$ & $35.79 \pm 9.96$ & $34.41 \pm 10.17$ \\
\hline $\begin{array}{l}\text { Left-foot } \\
\text { Lower-quarter } \\
\text { Y-balance test } \\
\text { (sec) }\end{array}$ & $31.21 \pm 8.41$ & $41.59 \pm 9.89^{*}$ & $38.39 \pm 10.62$ & $38.98 \pm 11.26$ \\
\hline
\end{tabular}

Table 4: The changes in skill fitness after 12-weeks exercise program.

The data are presented as mean \pm SD values.

${ }^{*}$ Significant $(\mathrm{p}<.05)$ difference between the baseline and 12 -week periods.

The changes in skill-related fitness between before and after the exercise program are shown in Table 4. Among the skill-related fitness factors, in the left-right turn hexagon agility test, no significant differences were observed between the 2 groups, and between the baseline and 12-week periods. In addition, the right-left foot lowerquarter Y-balance test results showed a significant difference between before and after the 12-week period in the exercise group $(p<.05)$. In the right foot lower-quarter Y-balance test, the changes after the completion of the exercise program in the exercise group were significant increases from the baseline values $(p=.092)$.

\begin{tabular}{|l|l|l|l|l|}
\hline & \multicolumn{2}{|l|}{ Exercise Group $(\mathrm{n}=8)$} & \multicolumn{2}{l|}{ Control Group $(\mathrm{n}=8)$} \\
\hline Variables & Before & After & Before & After \\
\hline d-ROM & 316.73 & 273.21 & $323.15 \pm 39.26$ & $328.94 \pm 35.14$ \\
$($ CARR. U. $)$ & \pm 34.32 & $\pm 31.62^{\star} \dagger$ & & \\
\hline BAP $(\mu \mathrm{mol} / \mathrm{L})$ & 2118.55 & 2311.71 & 2163.42 & $2236.23 \pm$ \\
& \pm 349.32 & \pm 452.13 & \pm 301.39 & 482.44 \\
\hline
\end{tabular}

The data are presented as mean \pm SD values.

${ }^{\star}$ Significant $(\mathrm{p}<.05)$ difference between the baseline and 12 -week periods. $\dagger$ Significant $(\mathrm{p}<.05)$ difference between the groups. 
Citation: Kim CG, Lee JS (2016) Effect of Complex Training Program on Physical Fitness, Derivatives Reactive Oxygen Metabolite and Biological Antioxidant Potential Levels of Adolescents with Intellectual Disabilities. Int J Phys Ther Rehab 2: 115. doi: http://dx.doi.org/10.15344/2455-7498/2016/115

Page 4 of 5

Changes in d-ROM and BAP levels after 12-weeks complex exercise program

The changes in $d-R O M$ and BAP levles after 12-weeks complex exercise program were detailed in Table 4 . The d-ROM levels were significantly increased after 12-weeks, and decreased more significantly in the exercise group than in the control group (respectively, $p<.05$ ). The BAP levels increased after completion of the exercise program in the exercise group $(p<.05)$. These results mean that 12 -weeks complex exercise program had positive effects on oxidative stress and antioxidant capacity.

\section{Discussion}

This study examined the effects of complex exercise program on physical fitness and d-ROM and BAP Levels in adolescents with intellectual disabilities.

People with intellectual disabilities have more difficulty performing intense physical activities without faltering than people without disabilities; thus, they have a greater tendency to be sedentary [22,23]. The weakened body coordination and movement ability in adolescents with intellectual disabilities result from their inability to smoothly control muscle groups in each body part [18]. In this study, the fitness of the exercise group significantly improved after the 12-weeks complex exercise program in terms of right-left grip strength, back strength, muscular endurance, and flexibility. In particular, back strength more significantly increased in the exercise group than in the control group. This result indicates that the combined exercise program conducted in this study induced improvement in muscular strength by stimulating different kinds of muscle groups through swiss ball exercises and improvement in coordination through basketball and soccer ball exercises. Moreover, in this study, the rightleft feet lower-quarter Y-balance test scores significantly increased in the exercise group after the 12 -week period $(p>.05)$, and the rightfoot lower-quarter Y-balance test scores more significantly increased in the exercise group than in the control group after 12-weeks ( $p=$ .092). A decline in physical balance ability occurs owing to muscle weakness, proprioceptive function deficiency, and decrease in range of motion [3,19,21]. Physical balance is an essential element of daily life and an important single factor in deciding a movement strategy [24]. Many advanced studies reported that exercise using tools such as swiss balls and elastic bands stimulates proprioceptive function, improves movement sensation function, and effectively facilitates neuromuscular control [25-26]. The lower-quarter Y-balance test was used in this study to assess functional balance ability. The results of this study indicate that the combined exercise program may be considered as effective for improving functional balance ability, which seemed to have resulted from the positive effect that the use of tools such as swiss balls had on neuromuscular control.

Meanwhile, ROS has high reactivity and a short life compared with stable oxygen in the air; thus, it can facilitate the onset of many diseases by impairing biogenic substances during hypergenesis. When the oxydative stress levels exceeds that of the antioxidative system, it confers a negative effect on the human body $[7,8]$. However, advanced studies demonstrated that continuous physical activities increase adaptability that suppress accumulation of oxidative stress and decrease the active oxygen level in the blood by improving the oxidative defense of the body [27]. In the present study, the d-ROM levels in the exercise group significantly decreased after 12-weeks complex exercise program compared with that in the control group.
This result is concurrent with those of advanced studies that reported improvement of cardiorespiratory function and oxydative stress levels in children who participated in an 8-weeks exercise program [28] and decreased oxidative stress in individuals who participated in regular exercise [29]. The previous studies reported that physical activities such as exercise could induce positive changes in active oxygen level $[30,31]$. However, significant changes were not observed in the BAP levels after the 12-weeks complex exercise program in this study. This result differs from that of other studies that reported that regular exercise increased the activity of antioxidative enzymes and decreased oxidative stress. In this regard, Kim et al. [32] reported that antioxidant capacity is affected by exercise intensity and duration. Indeed, many advanced studies demonstrated that exercises with greater intensity induce greater activation of oxydative stress and antioxidant capacity. The complex exercise program adopted in this study was conducted at low intensity, considering that the adolescent participants had intellectual disabilities; despite this, the subjects had difficulty performing the exercises consistently per session. Therefore, the effect of a complex exercise program with more intense exercises on the antioxidant capacity in adolescents with intellectual disabilities needs to be further investigated [33].

\section{Conclusion}

This study demonstrated that complex exercise program effectively improved physical fitness, BAP levels, and reduced d-ROM levels of the adolescents with intellectual disabilities. Therefore, it may be useful for enhancing the health and physical development of adolescents with intellectual disabilities.

\section{Conflict of interest}

The authors declare that they have no conflict of interest.

\section{Reference}

1. Takeuchi $E$ (1994) Incidence of obesity among school children with mental retardation in Japan. Am J Ment Retard 99: 283-288.

2. Sherrill C (2004) Adapted physical activity, recreation and sport: Crossdisciplinary and lifespan(6th ed.). Boston, Massachusetts: McGrawHill.

3. Wolfson L, Judge J, Whipple R, King M (1995) Strength is a major factor in balance, gait, and the occurrence of falls. J Gerontol A Biol Sci Med Sci 50 Spec No: 64-67.

4. Pitetti KH, Rimmer JH, Fernhall B (1993) Physical fitness and adults with mental retardation. An overview of current research and future directions. Sports Med 16: 23-56.

5. Alessio HM (1993) Exercise-induced oxidative stress. Med Sci Sports Exerc 25: 218-224.

6. Halliwell B, Gutteridge $\mathrm{J}(2007)$ Free radicals in biology and medicine (4th ed). Clarendon Press Oxford.

7. Gröger M, Speit G, Radermacher P, Muth CM (2005) Interaction of hyperbaric oxygen, nitric oxide, and heme oxygenase on DNA strand breaks in vivo. Mutation Res 572: 167-172.

8. Oter S, Korkmaz A, Topal T, Ozcan O, Sadir S, et al. (2005) Correlation between hyperbaric oxygen exposure pressures and oxidative parameters in rat lung, brain, and erythrocytes. Clin Biochem 38: 706-711.

9. Jenkins RR, Friedland R, Howald H (1984) The relationship of oxygen uptake to superoxide dismutase and catalase activity in human skeletal muscle. Int J Sports Med 5: 11-14.

10. Miyazaki H, Oh-ishi S, Ookawara T, Kizaki T, Toshinai K, et al. (2001) Strenuous endurance training in humans reduces oxidative stress following exhausting exercise. Eur J Appl Physiol 84: 1-6. 
Citation: Kim CG, Lee JS (2016) Effect of Complex Training Program on Physical Fitness, Derivatives Reactive Oxygen Metabolite and Biological Antioxidant Potential Levels of Adolescents with Intellectual Disabilities. Int J Phys Ther Rehab 2: 115. doi: http://dx.doi.org/10.15344/2455-7498/2016/115

Page 5 of 5

11. American College of Sports Medicine (2009) ACSM's guidelines for exercise testing and prescription (8th Ed.). Lippincott Williams \& Wilkins.

12. Ashton T, Rowlands CC, Jones E (1998) Electron spin resonance spectroscopic detection of oxygen-centered radicals in human serum following exhaustive exercise. Eur J Appl Physiol 77: 498-502.

13. Bloomer RJ, Goldfarb AH (2004) Anaerobic exercise and oxidative stress: a review. Can J Appl Physiol 29: 245-263.

14. Sureda A, Ferrer MD, Tauler P, Romaguera D, Drobnic F, et al. (2009) Effects of exercise intensity on lymphocyte $\mathrm{H} 2 \mathrm{O} 2$ production and antioxidant defences in soccer players. Br J Sports Med 43: 186-190.

15. Close GL, Ashton T, Cable T, Doran D, MacLaren DP (2004) Eccentric exercise, isokinetic muscle torque and delayed onset muscle soreness: the role of reactive oxygen species. Eur J App Physiol 91: 615-621.

16. Groussard C, Rannou-Bekono F, Machefer G, Chevanne M, Vincent S, et al. (2003) Changes in blood lipid peroxidation markers and antioxidants after a single sprint anaerobic exercise. Eur J Appl Physiol 89: 14-20.

17. Ramel A, Wagner KH, Elmadfa I (2004) Plasma antioxidants and lipid oxidation after submaximal resistance exercise in men. Eur J Nutr 43: 2-6.

18. Dixon-Ibarra A, Lee M, Dugala A (2013) Physical activity and sedentary behavior in older adults with intellectual disabilities: a comparative study. Adapt Phys Activ Q 30: 1-19.

19. Naofumi T, Takaaki T, Takayuki M, Daisuke E, Reiko Y, et al. (2008) Relationship between periodontal condition and plasma reactive oxygen metabolites in patients in the maintenance phase of periodontal teatment. J Periodont 79: 2136-2142.

20. Komatsu F, Kagawa Y, Sakuma M, Kawabata T, Kaneko Y, et al. (2006) Investigation of oxidative stress and dietary habits in Mongolian people, compared to Japanese people. Nutr Metab (Lond) 3: 21.

21. Kim CG, Lee JS (2013) Differences of d-ROM, BAP, and Metabolic Variables with Acute Isokinetic Strength and Muscular Endurance Protocols. Korea J Sports Sci 22: 1357-1367.

22. Magee DJ (2008) Orthopaedic physical assessment. Elsevier Health Sciences.

23. Priplata AA, Patritti BL, Niemi JB, Hughes R, Gravelle DC, et al. (2006) Noise-enhanced balance control in patients with diabetes and patients with stroke. Ann Neurol 59: 4-12.

24. Keays KS, Harris SR, Lucyshyn JM, Maclntyre DL (2008) Effects of Pilates exercises on shoulder range of motion, pain, mood, and upper-extremity function in women living with breast cancer: a pilot study. Phys Ther 88 : 494-510

25. Carmeli E, Bar-Chad S, Lotan M, Merrick J, Coleman R (2003) Five clinical tests to assess balance following ball exercises and treadmill training in adult persons with intellectual disability. J Gerontol A Biol Sci Med Sci 58 : 767-772.

26. Lord SR, Clark RD, Webster IW (1991) Physiological factors associated with falls in an elderly population. J Am Geriatr Soc 39: 1194-1200.

27. Marshall PW, Murphy BA (2005) Core stability exercises on and off a Swiss ball. Arch Phys Med Rehabil 86: 242-249.

28. Sumida S, Tanaka K, Kitao H, Nakadomo F (1989) Exercise-induced lipid peroxidation and leakage of enzymes before and after vitamin $\mathrm{E}$ supplementation. Int J Biochem 21: 835-838.

29. Onur E, KabaroÄŸlu C, GÃ $1 / 4$ nay O, Var A, Yilmaz O, et al. (2011) The beneficial effects of physical exercise on antioxidant status in asthmatic children. Allergol Immunopathol (Madr) 39: 90-95.

30. Aoi W, Sakuma K (2011) Oxidative stress and skeletal muscle dysfunction with aging. Current aging science 4: 101-109.

31. Davies KJ, Quintanilha AT, Brooks GA, Packer L (1982) Free radicals and tissue damage produced by exercise. Biochem Biophys Res Commun 107 1198-1205.

32. Rarick GL, McQuillan JP (1977) The factor structure of motor abilities of trainable mentally retarded children: Implications for curriculum development. Department of Physical Education, University of California.

33. Rimmer JH, Riley B, Wang E, Rauworth A, Jurkowski J (2004) Physical activity participation among persons with disabilities: barriers and facilitators. Ame J Preven Med 26: 419-425. 